\title{
THE EFFECT OF ANISOTROPY ON THE CREEP OF POLYGRYSTALLINE ICE
}

\author{
By R. C. LILE
}

(Meteorology Department, University of Melbourne, Parkville, Victoria 3052 , Australia)

\begin{abstract}
Quantitative effects of crystallographic orientation fabrics are incorporated into the flow law for isotropic polycrystalline ice by the introduction of an enhancement factor applied to the isotropic fluidity. An aggregate is viewed to a first approximation as a collection of grains deforming independently by basal glide. The influence of preferred orientations on the mean intragranular rate of strain is treated in terms of a redistribution of the magnitude and orientation of resolved basal shear stress. A quantitative measure of this effect on the fluidity of the aggregate is provided through the development of a geometric tensor and a stress configuration parameter. Intergranular interference is then considered as a dissipative process modifying the fluidity of the aggregate.

Empirical justification for the model at low octahedral shear stresses is provided by several laboratory creep tests on naturally anisotropic bore-hole specimens under both in situ and anomalous stress situations. Predicted enhancement factors ranged from approximately 0.2 to 2.8 and agree well with measured values. The tests were carried out in uniaxial compression and simple shear.
\end{abstract}

RÉsumé. Effet d'anisotropie sur le fluage de la glace polycristalline. Des effets quantitatifs liés à l'orientation cristallographique résultant de la texture sont pris en considération dans la loi d'écoulement généralement utilisée pour la glace polycristalline isotrope en associant un facteur d'accroissement à la fluidité isotrope. Un agrégat est considéré en première approximation comme un ensemble de grains indépendants se déformant d'abord par glissement basal. L'influence des orientations préférentielles sur la vitesse moyenne de déformation intergranulaire est traitée en terme d'une redistribution de la grandeur et de l'orientation de la contrainte de cisaillement réduite dans le plan basal. Une mesure quantitative de cet effet sur la fluidité de l'agrégat est obtenue à l'aide du développement d'un tenseur géométrique et d'un paramètre lié à la configuration de la contrainte. L'accomodation intergranulaire est ensuite considérée comme un processus dissipatif modifiant la fluidité de l'agrégat.

La justification expérimentale du modèle dans le cas de faibles contraintes de cisaillement octaédriques est faite grâce à plusieurs essais de fluage en laborátoire sur des carottes de glace naturelle anisotropes à la fois sous des contraintes, correspondant à celles existant dans les glaciers, et, des contraintes exceptionnelles. Les facteurs d'accroissement prévus ont des valeurs comprises entre 0,2 et 2,8 et correspondent bien aux valeurs mesurées. Les essais sont faits par compression uniaxiale et par cisaillement simple.

Zusammenèassung. Der Einfluss der Anisotropie auf das Kriechen von polykristallinem Eis. Quantitative Einflüsse der kristallographischen Orientierungsstruktur werden in das Fliessgesetz für isotropes polykristallines Eis einbezogen, indem ein Steigerungsfaktor der isotropen Fliessfähigkeit eingeführt wird. Ein Aggregat wird in erster Näherung als eine Ansammlung von Körnern betrachtet, die unabhängig voneinander durch basales Gleiten verformt werden. Der Einfluss bevorzugter Orientierungen auf die mittlere Dehnungsgeschwindigkeit in den Körnern wird durch eine Neuverteilung der basalen Schubspannung nach Grösse und Orientierung berücksichtigt. Ein quantitatives Mass dieser Auswirkung auf die Fliessfähigkeit des Aggregats wird durch die Entwicklung eines geometrischen Tensors und eines Spannungskonfigurationsparameters gegeben. Gegenseitige Beeinträchtigung der Körner wird dann als dissipativer Vorgang betrachtet, der die Fliessfähigkeit des Aggregats verändert.

Das Modell wird bei niedrigen oktaedrischen Schubspannungen durch mehrere Kriechversuche im Labor an natürlich anisotropen Bohrlochproben empirisch bestätigt, sowohl unter in situ- als auch unter anomalen Spannungsbedingungen. Die vorausgesagten Steigerungsfaktoren erstrecken sich von ungefähr 0,2 bis 2,8 und stimmen gut mit gemessenen Werten überein. Die Versuche wurden unter einachsigem Druck und einfachem Schub ausgeführt.

\section{Introduction}

Empirical flow laws for polycrystalline ice presently in use are based for the most part on the suite of existing data relating to tesselate, fine-grained, isotropic polycrystals. Quantitative effects of preferred crystallographic orientation fabrics are here incorporated into the flow law for an isotropic polycrystal by the introduction of an enhancement factor applied to the isotropic fluidity.

The flow law for polycrystalline ice relates the rate of strain tensor $\dot{\epsilon}_{i j}$ to the stress tensor $\sigma_{i j}$. Assuming that hydrostatic pressure does not effect the flow law, Glen (1958) showed that $\dot{\epsilon}_{i j}$ is related to the deviatoric stress tensor $\sigma_{i j}{ }^{\prime}$ through functions of the second and third deviatoric stress invariants

$$
\Sigma_{2}{ }^{\prime}=\frac{1}{2} \sigma_{i j} \sigma_{i j}{ }^{\prime}
$$




$$
\Sigma_{3}{ }^{\prime}=\frac{1}{3} \sigma_{i j}{ }^{\prime} \sigma_{j k}{ }^{\prime} \sigma_{k i}{ }^{\prime} .
$$

In constructing a rheological model to investigate the effects of anisotropy it is useful to recognize the physical characteristics described by these invariants.

$\Sigma_{2}^{\prime}$ is frequently specified in terms of the octahedral shear stress

$$
\begin{aligned}
\tau_{0} & \equiv\left(\sigma_{i j} \sigma_{i j}{ }^{\prime} / 3\right)^{\frac{1}{2}} \\
& =\left(2 \Sigma_{2} / 3\right)^{\frac{1}{2}} \\
& =\frac{2}{3}\left(\tau_{1}^{2}+\tau_{2}{ }^{2}+\tau_{3}^{2}\right)^{\frac{1}{2}},
\end{aligned}
$$

where the $\tau_{i}$ are the principal shear stresses related by the expression (Jaeger, [ ${ }^{\mathrm{c}}{ }_{1969}$ ])

$$
\tau_{1}-\tau_{2}+\tau_{3}=0 \text {. }
$$

A zero subscript hereafter denotes the octahedral value of the associated tensor defined as in Equation (2). As $\Sigma_{2}^{\prime}$ is $\left(\frac{5}{3}\right)$ times the mean square shear stress evaluated over all surface orientations, $\tau_{0}$ is proportional to the root-mean-square $(\mathrm{rms})$ shear stress.

The third deviatoric stress invariant contains information related to stress configuration. When dependence on $\Sigma_{2}{ }^{\prime}$ is eliminated from $\Sigma_{3}{ }^{\prime}$ by scaling the components of $\sigma_{i j}{ }^{\prime}$ to an octahedral value of $2^{1 / 6}$, the resulting normalized value of $\Sigma_{3}^{\prime}$ ranges from +1 for uniaxial tension through zero for pure shear in two dimensions to -1 for uniaxial compression. A more convenient stress configuration parameter is realized by defining the third deviatoric stress invariant in terms of the principal shear stresses. The invariant

$$
\Lambda=\left(\tau_{3}-\tau_{1}\right) / \tau_{2},
$$

is non-dimensional and independent of $\Sigma_{2}{ }^{\prime}$ while retaining the symmetry and unity limits exhibited by the normalized form of $\Sigma_{3}{ }^{\prime}$.

Specification of the independent physical invariants $\tau_{0}$ and $\Lambda$ together with the orientation of the principal axes of stress is sufficient to define an arbitrary deviatoric stress situation. A precise definition of an arbitrary orientation fabric $f$ will also be required. Let $f$ be defined as the volume fraction per steradian of an aggregate of total volume $V$ possessing optic axes oriented within the elemental solid angle $\mathrm{d} \Omega$ :

$$
f=\frac{\mathbf{I}}{V} \frac{\mathrm{d} V}{\mathrm{~d} \Omega} .
$$

It follows that the orientation density of an isotropic aggregate, which we shall call $f^{\prime}$, is $f=f^{\prime}=(2 \pi)^{-1}$.

Consider an aggregate in which the octahedral strain rate $\dot{\epsilon}_{\mathrm{o}}$ is a function of the rms resolved basal shear stress, as may be expected if the rate-controlling process is basal glide. Jaeger ([ $\left.\left.{ }^{1}{ }_{1} 69\right]\right)$ shows that the shear stress resolved on a basal plane with direction cosines $l_{i}$ relative to the principal axes of stress is

$$
\tau_{\mathrm{B}}=2\left(\tau_{\mathrm{I}}^{2} l_{2}^{2} l_{3}^{2}+\tau_{2}^{2} l_{\mathrm{I}}^{2} l_{3}^{2}+\tau_{3}^{2} l_{\mathrm{I}}^{2} l_{2}^{2}\right)^{\frac{1}{2}} .
$$

Eliminating the $\tau_{i}$ in Equation (6) using Equations (2), (3), and (4) yields

$$
\tau_{\mathrm{B}}=\alpha \tau_{0},
$$

where

$$
\alpha=\frac{3}{\sqrt{ } 2}\left[\frac{(\Lambda-\mathrm{I})^{2} l_{2}{ }^{2} l_{3}{ }^{2}+4 l_{1}^{2} l_{3}{ }^{2}+(\Lambda+\mathrm{I})^{2} l_{1}{ }^{2} l_{2}{ }^{2}}{\Lambda^{2}+3}\right]^{\frac{1}{2}},
$$

is the geometric stress factor (Weertman, 1973) for the grain.

Defining the rms resolved basal shear stress as

$$
\tau_{\mathrm{rms}}=\left[\frac{\mathrm{I}}{V} \int_{V} \tau_{\mathrm{B}^{2}} \mathrm{~d} V\right]^{\frac{1}{2}}
$$


and substituting Equations (5) and (7) gives

$$
\tau_{\mathrm{rms}}=\left[\int_{0}^{2 \pi} f \alpha^{2} \mathrm{~d} \Omega\right]^{\frac{1}{2}} \tau_{0} .
$$

Equation (10) may be evaluated for an isotropic aggregate using

$$
\left.\begin{array}{rl}
l_{1} & =\sin \theta \cos \alpha, \\
l_{2} & =\sin \theta \sin \alpha, \\
l_{3} & =\cos \theta, \\
\mathrm{d} \Omega & =\sin \theta \mathrm{d} \theta \mathrm{d} \alpha .
\end{array}\right\}
$$

The result is

$$
\tau_{\mathrm{rms}}=\tau_{0} \sqrt{ }(3 / \mathrm{ro}),
$$

notably independent of $\Lambda$. If, as proposed above, $\dot{\epsilon}_{0}$ is a function of $\tau_{\mathrm{rms}}$, the implication of Equation (12) is that for an isotropic aggregate $\dot{\epsilon}_{0}$ is a function of $\tau_{0}$ and not of stress configuration. This suggests a flow law of the form (Nye, I953)

$$
\dot{\epsilon}_{0}=\lambda\left(\tau_{0}\right) \tau_{0} .
$$

The large suite of empirical creep data applicable to isotropic polycrystals presently available indicates (cf. Weertman, I973) that $\dot{\epsilon}_{0} \propto \tau_{0}{ }^{n}$, implying (Nye, I953; Langdon, 1973) that $\lambda \propto\left(\tau_{0} / G\right)^{n-1}$ where $G$ is the shear modulus for ice.

Weertman ( 1963$)$ viewed an ice polycrystal as a collection of grains deforming independently by basal glide governed by a monocrystalline flow law of the form

$$
\dot{\epsilon}_{\mathrm{B}}=\lambda_{\mathrm{B}} \tau_{\mathrm{B}}
$$

where $\dot{\epsilon}_{\mathrm{B}}$ is the basal glide rate and $\lambda_{\mathrm{B}} \propto\left(\tau_{\mathrm{B}} / G\right)^{n-1}$ is the basal fluidity. Assuming an isotropic aggregate in uniaxial compression under an axial stress $\sigma_{\mathrm{a}}\left(=3 \tau_{0} / \sqrt{2}\right)$ and using an axial geometric strain-rate factor $\left(b_{\mathrm{a}}\right)$ to resolve $\dot{\epsilon}_{\mathrm{B}}$ into its axial component, he found the average resolved axial strain-rate to be

$$
\overline{\dot{\epsilon}}_{\mathrm{a}}=\lambda_{\mathrm{B}} \beta \overline{b_{\mathrm{a}} \alpha} \tau_{0} .
$$

An additional factor $(\beta)$ was introduced to account for effects of intergranular interference; the factor $\left(\lambda_{\mathrm{B}} \beta \overline{b_{\mathrm{a}} \alpha}\right)$ is the axial fluidity of the aggregate. As the axial geometric strain-rate factor $b_{\mathrm{a}}$ is only one component of a general transformation tensor $b_{i j}$, Equation (15) may be written for each component of $\bar{\epsilon}_{i j}$ :

$$
\overline{\dot{\epsilon}}_{i j}=\lambda_{i j} \tau_{0} .
$$

Equation (I6) may be regarded as a flow law for anisotropic ice deforming in an arbitrary stress situation, the tensor fluidity $\lambda_{i j}=\lambda_{\mathrm{B}} \beta \overline{b_{i j} \alpha}$ accounting for the effects of $f$ and $\Lambda$ through the composite geometric tensor

$$
\bar{\alpha}_{i j}=\overline{b_{i j} \alpha}=\int_{2 \pi} f b_{i j} \alpha(\Lambda) \mathrm{d} \Omega .
$$

If the symmetric part of $\bar{\alpha}_{i j}$ is written $\bar{g}_{i j}$, then the octahedral deformation rate of the aggregate is $\bar{\gamma}_{0}=\lambda_{0} \tau_{0}$, where

$$
\lambda_{\mathrm{o}}=\lambda_{\mathrm{B}} \beta(f, \Lambda) \bar{g}_{0}(f, \Lambda) .
$$

Finally, consider two aggregates differing only with regard to their orientation fabrics and deforming under identical conditions of temperature, stress situation, etc. If one is isotropic, the ratio of their octahedral deformation rates is 


$$
\begin{aligned}
E & =\frac{\overline{\dot{\gamma}}_{0}(f, \Lambda)}{\overline{\dot{\gamma}}_{0}\left(f^{\prime}\right)} \\
& =\frac{\lambda_{0}(f, \Lambda)}{\lambda_{0}\left(f^{\prime}\right)}=\frac{\beta(f, \Lambda) \bar{g}_{0}(f, \Lambda)}{\beta\left(f^{\prime}\right) \bar{g}_{0}\left(f^{\prime}\right)} .
\end{aligned}
$$

Equation (19) provides a flow law for an arbitrary orientation fabric and stress situation through application of an enhancement factor $E$ to the flow law for an isotropic aggregate.

As a beginning, the present paper examines the results to be expected at small octahedral shear stresses where both laboratory and field data indicate an approach to a linear stressstrain-rate dependence $(n=\mathbf{I})$. The geometric tensor, interference factor, and enhancement factor are considered further in Sections 2, 3, and 4, respectively. In Section 5 the results of several specially designed creep tests are provided to establish an empirical justification for the model.

\section{The GeOMETRIC TENSOR}

If it is assumed that the basal glide rate is directed parallel to (Kamb, I96I) and is linearly proportional to the resolved basal shear stress, then $\dot{\epsilon}_{\mathrm{B}}=\lambda_{\mathrm{B}} \alpha \tau_{\mathrm{o}}$ while $\lambda_{\mathrm{B}}$ is independent of stress. Let $\dot{\epsilon}_{i j} \mathrm{~B}$ be the strain-rate of the grain in a coordinate system $x_{i}{ }^{\mathrm{B}}$ associated with the basal plane such that $x_{\mathrm{I}} \mathrm{B}$ is parallel to $l_{i}$ and $x_{3} \mathrm{~B}$ is oriented parallel to the resolved shear stress. The strain-rate of the grain in the principal stress coordinates is then given by the transformation

$$
\dot{\epsilon}_{i j}=c_{k i} c_{l j} \dot{\epsilon}_{k l}{ }^{\mathrm{B}},
$$

where $c_{p q}$ is the cosine of the angle between the positive $x_{p}{ }^{\mathrm{B}}$ axis and the positive $x_{q}$ axis. As the only non-vanishing component of $\dot{\epsilon}_{k l} l^{\mathrm{B}}$ is $\dot{\epsilon}_{3 \mathrm{I}}{ }^{\mathrm{B}}=\dot{\epsilon}_{\mathrm{B}}$, Equation (20) simplifies, becoming

$$
\dot{\epsilon}_{i j}=c_{3 i} c_{1 j} \alpha \lambda_{\mathrm{B}} \tau_{0},
$$

where $c_{3 i}=l_{i}$ and $c_{1 j}=c_{1 j}\left(\Lambda, l_{j}\right)$ is a unit vector parallel to the resolved shear stress. Let the geometrically related factors on the right-hand side of Equation (2I) be absorbed into the composite geometric tensor $\alpha_{i j}=c_{3 i} c_{1} \alpha=b_{i j} \alpha$.

The bulk strain-rate of the non-interacting aggregate is obtained by forming the volumetric mean granular rate of strain:

$$
\overline{\dot{\epsilon}}_{i j}=\frac{\mathrm{I}}{V} \int_{V} \dot{\epsilon}_{i j} \mathrm{~d} V .
$$

Substitution of Equations (2 I), (I 7), and (5) into (22) gives

$$
\overline{\dot{\epsilon}}_{i j}=\bar{\alpha}_{i j} \lambda_{\mathrm{B}} \tau_{0} \text {. }
$$

It follows that the octahedral deformation rate of the non-interacting aggregate is

$$
\bar{\gamma}_{0 \mathrm{~N}}=\lambda_{0 \mathrm{~N}} \tau_{0},
$$

where

$$
\lambda_{0 \mathrm{~N}}=\bar{g}_{0} \lambda_{\mathrm{B}}
$$

\section{The interference factor}

A sufficient condition for accommodation at grain boundaries is that each grain conform individually to the bulk flow situation (Taylor, 1956). Then each grain must carry out a rotational and deformational adjustment $\dot{a}_{i j}=-\left(\dot{\epsilon}_{i j}-\dot{\epsilon}_{i j}\right)$, where $\dot{a}_{i j}$ is the granular rate of interference. The specific rate of dissipation associated with the adjustment is $q=\frac{1}{3} \dot{a}_{i j} \sigma_{i j}$. Since the process is dissipative, the rate of dissipation for the aggregate is given by the rootmean-square granular rate 


$$
\bar{q}=\left[\frac{\mathrm{I}}{V} \int_{V}\left(\frac{1}{3} \dot{a}_{i j} \sigma_{i j^{\prime}}\right)^{2} \mathrm{~d} V\right]^{\frac{1}{2}} .
$$

The simplifying approximation

$$
\left(\frac{1}{3} a_{i j} \sigma_{i j}\right)^{2} \approx \frac{1}{3} \tau_{0}^{2}\left(\dot{a}_{i j}\right)^{2}
$$

retains first-order interference effects. Hence, substituting Equation (27) into Equation (26),

$$
\begin{aligned}
\bar{q} & \approx \tau_{0}\left[\frac{\mathrm{I}}{3 V} \int_{V}\left(\dot{a}_{i j}\right)^{2} \mathrm{~d} V\right]^{\frac{1}{2}} \\
& =\tau_{0}\left[\frac{\mathrm{I}}{3} \int_{2 \pi} f\left(\dot{\epsilon}_{i j}-\overline{\dot{\epsilon}}_{i j}\right)^{2} \mathrm{~d} \Omega\right]^{\frac{1}{3}} \\
& =\lambda_{\mathrm{B}} \tau_{0}^{2}\left[\overline{\alpha_{0}^{2}}-\bar{\alpha}_{0}^{2}\right]^{\frac{1}{2}},
\end{aligned}
$$

where

$$
\overline{\alpha_{0}^{2}} \equiv \int_{0}^{2 \pi} f \alpha_{0}{ }^{2} \mathrm{~d} \Omega=\frac{1}{3} \int_{0}^{2 \pi} f \alpha^{2} \mathrm{~d} \Omega .
$$

The effect of this dissipation is an increase in the aggregate viscosity. If $\lambda_{0 \mathrm{~N}^{-1}}$ is the ambient viscosity prior to the inclusion of interference effects and $\lambda_{0}{ }^{-1}$ is the inclusive viscosity, we may write after Batchelor (1967, equation 4.11.16)

$$
\bar{q}=6\left(\lambda_{0}{ }^{-1}-\lambda_{0 \mathrm{~N}^{-1}}\right) \overline{\dot{\gamma}}_{0 \mathrm{~N}^{2}},
$$

where $\overline{\dot{\gamma}}_{\mathrm{ON}}$ is the ambient non-interacting octahedral deformation rate given by Equation (24). Eliminating $\bar{q}$ between Equations (28) and (30) and introducing Equations (24) and (25) yields

$$
\lambda_{0} \approx \bar{g}_{0} \lambda_{\mathrm{B}}\left[\mathrm{I}+\left(\frac{\overline{\alpha_{0}^{2}}-\bar{\alpha}_{0}^{2}}{36 \bar{g}_{0}^{2}}\right)^{\frac{1}{2}}\right]^{-\mathrm{I}} .
$$

Finally, eliminating the ratio $\lambda_{\mathrm{o}} / \lambda_{\mathrm{B}}$ between Equations (18) and (3I) yields a first-order estimate of the interference factor

$$
\beta \approx\left[\mathrm{I}+\left(\frac{\overline{\alpha_{0}^{2}}-\bar{\alpha}_{0}^{2}}{3^{6} \bar{g}_{0}^{2}}\right)^{\frac{1}{2}}\right]^{-\mathrm{I}} .
$$

\section{The enhancement factor}

The analytical integration of Equation (I 7) for an isotropic orientation density using Equations (I I) and the subsequent evaluation of the aggregate octahedral geometric factor yields*

$$
\bar{\alpha}_{0}\left(f^{\prime}\right)=\bar{g}_{0}\left(f^{\prime}\right)=\frac{1}{5} .
$$

Combining Equations (29), (I0), and (12) leads to the result

$$
\overline{\alpha_{0}^{2}}\left(f^{\prime}\right)=\frac{1}{5} \text {. }
$$

The isotropic interference factor may then be found by substituting the above values into Equation (32), obtaining

$$
\beta\left(f^{\prime}\right)=\frac{3}{4}
$$

\footnotetext{
* Further details will be included in the thesis, now in preparation for submission for the degree of Ph.D. at the University of Melbourne by the present author under the title "Rheology of polycrystalline ice". 
It follows, using Equation (19), that the octahedral enhancement factor for an anisotropic aggregate is

$$
E=\frac{20}{3} \beta(f, \Lambda) \bar{g}_{0}(f, \Lambda) .
$$

For a given orientation fabric and stress configuration Equations (17), (29), and (32) must then be integrated numerically to obtain $E(f, \Lambda)$.

The typical creep set-up yields only that strain-rate component associated with the direction of the applied load. Thus, if the model is to be tested conveniently or applied generally to past anisotropic creep results, a definition of component fluidity enhancement is needed. A practical definition is complicated by the need to identify a coordinated system in which the applied load may be expressed as a single tensor component. For uniaxial and simple shear (Jaeger, [ $\left.{ }^{\mathrm{c}} \mathrm{I} 969\right]$ ) tests between parallel opposed platens, the required system $x_{i} \mathrm{P}$ is clearly associated directly with platen orientation. Let $x_{\mathrm{I}} \mathrm{P}$ be directed parallel to the applied shear stress (if any) and $x_{3}{ }^{\mathrm{P}}$ be directed parallel to the platen normal and away from the specimen. It follows that the measured uniaxial and simple shear components are $\overline{\dot{\epsilon}}_{33} \mathrm{P}$ and $\dot{\bar{\epsilon}}_{3 \mathrm{I}} \mathrm{P}$, respectively. If $\bar{g}_{i j} \mathrm{P}$ is the geometric tensor expressed in the $x_{i} \mathrm{P}$ system, the appropriate component enhancements are*

$$
E_{33} \mathrm{P}(f)=\frac{20}{3 \sqrt{ } 2} \bar{g}_{33} \mathrm{P}(f) \beta(f),
$$

for uniaxial compression, and

$$
E_{3 \mathrm{I}} \mathrm{P}(f)=\frac{20 \sqrt{ } 2}{3 \sqrt{ } 3} \bar{g}_{3 \mathrm{I}} \mathrm{P}(f) \beta(f),
$$

for simple shear.

\section{Results}

In view of the paucity of suitably documented creep tests on anisotropic polycrystals, several experiments were designed specifically to provide empirical as well as model-derived enhancements in uniaxial compression $(\Lambda=-\mathrm{I})$ and simple shear $(\Lambda=0)$. The results of these tests are reported in this section.

Anisotropic ice cores were obtained from two quite different stress situations at Law Dome, Antarctica. These cores have been subjected in the laboratory to stress configurations simulating both in situ and anomalous conditions. Three specimens were prepared from the $3 \mathrm{r} 8 \mathrm{~m}$ core at site SGD, the Dome Summit, a region of uniaxial compression $(\Lambda=-\mathrm{I})$. The girdle fabric of the parent core is illustrated in Figure Ic. Two of the specimens $\left(3 \mathrm{I} 8 \mathrm{D}_{\mathrm{I}}\right.$
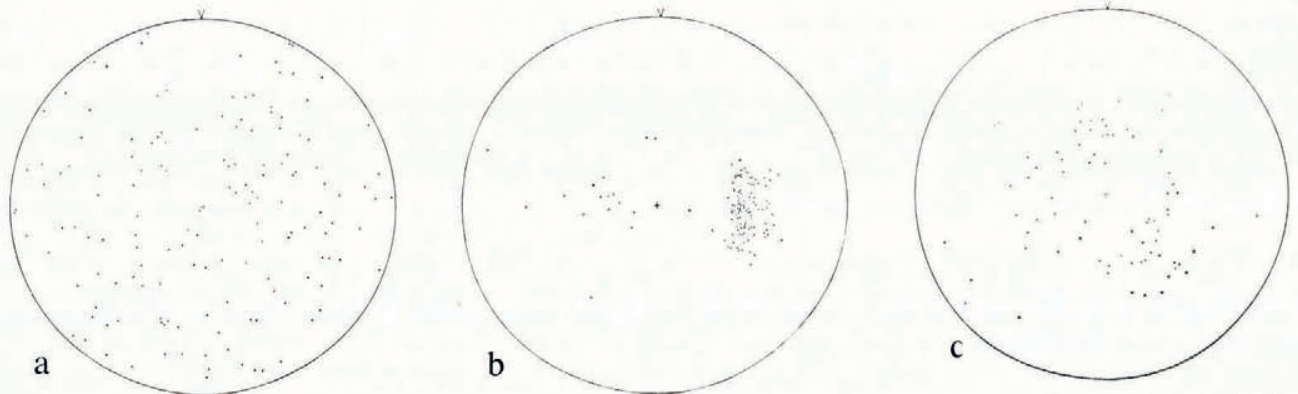

Fig. I. Fabrics of (a) laboratory-prepared isotropic ice, (b) Cape Folger core from $200 \mathrm{~m}$ depth sectioned at $45^{\circ}$ to the horizontal and $(c)$ a horizontal section of Dome Summit core from ${ }^{1} 8 \mathrm{~m}$ depth.

* For further details see the author's doctoral thesis. 
and $\left.3_{1} \mathbf{1 D D}_{2}\right)$ were loaded in uniaxial compression as in situ. The third specimen $\left(3 \mathrm{I}_{3} \mathrm{D}_{3}\right)$ was tilted $90^{\circ}$ to the in situ case with the axis of compression normal to the axis of symmetry of the girdle fabric. The octahedral shear stress and temperature in each of the tests were $0.005 \mathrm{MN} \mathrm{m}^{-2}$ and $-10.2^{\circ} \mathrm{C}$, respectively.

A second set of three specimens was prepared from the $200 \mathrm{~m}$ core at site SGF near Cape Folger. The parent core exhibited a strong single-pole fabric (Fig. I(b)), indicative of its

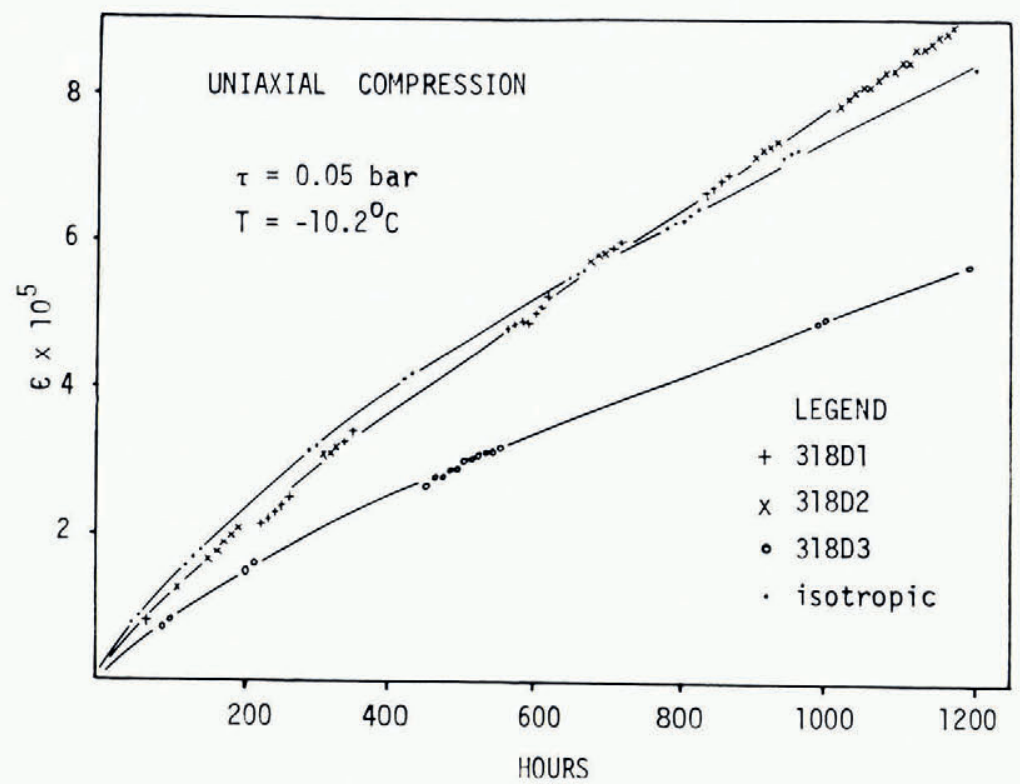

Fig. 2. Creep curves of axial strain versus time for specimens in uniaxial compression.

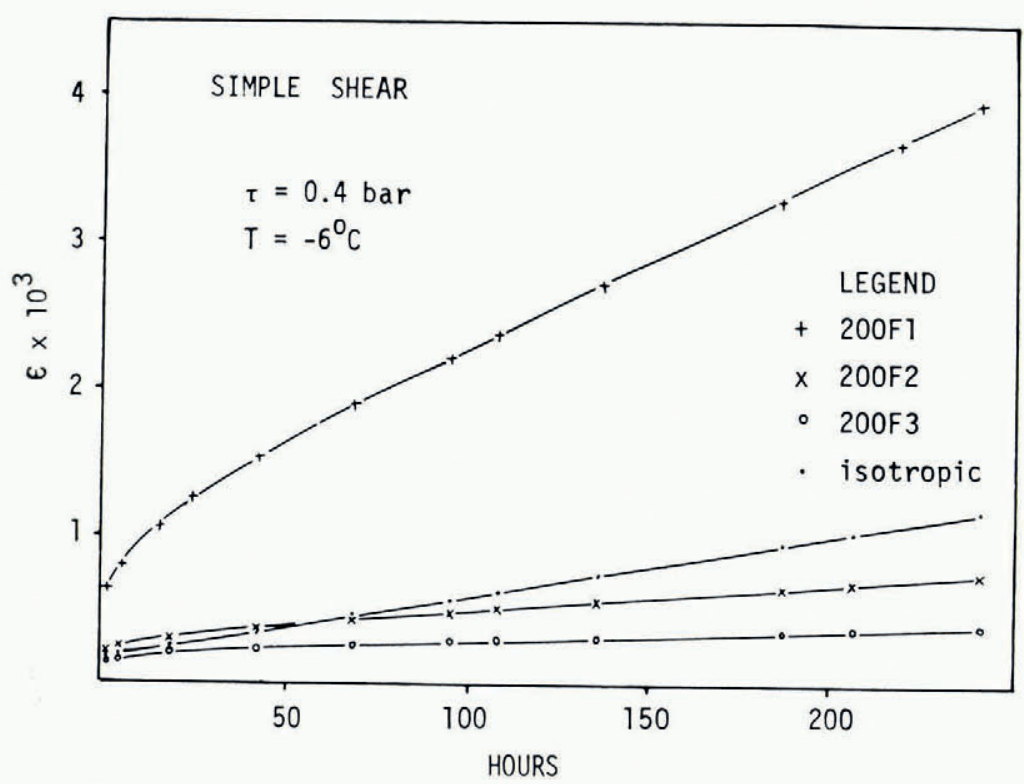

Fig. 3. Creep curves of shear strain versus time for specimens in simple shear. 
history of simple shear (Jaeger, $\left[{ }^{\mathrm{c}}{ }^{1} 969\right]$ ) flow in that region. In order to reinstate the in situ stress configuration $(\Lambda=0)$, these specimens were mounted between parallel platens and a constant shear load applied. The plattens were constrained to remain equidistant to simulate the in situ situation of simple shear flow. Specimen $200 \mathrm{~F}_{\mathrm{I}}$ was oriented as in situ (single-pole axis normal to the platens) while the single pole axes of specimens $200 \mathrm{~F}_{2}$ and $200 \mathrm{~F}_{3}$ were tilted at $22.5^{\circ}$ and $45^{\circ}$, respectively, to the platen normal into the direction of the applied shear stress. These tests were carried out at $0.04 \mathrm{MN} \mathrm{m}^{-2}$ octahedral and $-6.0^{\circ} \mathrm{C}$.

With each set, an isotropic aggregate of similar grain size was tested under identical conditions. A typical orientation fabric for these laboratory-prepared samples is shown in Figure $1(a)$. Figures 2 and 3 show the creep curves obtained for the uniaxial and shear tests, respectively.

Steady-state secondary creep rates were required to evaluate the observed component enhancements. Reference to Figure 3 suggests that the samples deforming in simple shear had settled to steady-state creep rates during the latter half of the experiment. Slopes of the creep curves for the period from 140 to $240 \mathrm{~h}$ were thus used to calculate the observed shear enhancements.

At the lower temperature and smaller octahedral shear stress used in the uniaxial experiment, the duration of the primary stage of creep was much longer. The residual curvature at the conclusion of the experiment (Fig. 2) appears to be less for the pre-strained bore-hole material than for the isotropic sample. Therefore it may be expected that the observed axial enhancements, based on the slopes of the creep curves between I ooo and I $200 \mathrm{~h}$, slightly underestimate the actual steady-state axial enhancements. The observed component enhancement for each of the six anisotropic specimens with respect to its associated isotropic control sample is entered in Table I.

TABLE I. OBSERVED AND MODEL-DERIVEd COMPONENT ENHANCEMENTS

\begin{tabular}{lccccc} 
& \multicolumn{5}{c}{ Experiment } \\
& $3^{1} 8 D_{I} / 2$ & $3{ }^{2} 8 D_{3}$ & $200 F_{1}$ & $200 F_{2}$ & $200 F_{3}$ \\
Computed & 1.47 & 0.86 & 2.79 & 0.45 & 0.21 \\
Observed & $1.4 \mathrm{I}$ & 0.83 & 2.78 & 0.43 & 0.22
\end{tabular}

For each test, the measured orientation fabric, stress configuration, and tilt orientation of the specimen were presented as inputs to a computer program which performed the numerical integrations and calculations necessary to evaluate the component enhancements. The resulting estimates of the component enhancements calculated from the model are listed in Table I above the observed enhancements.

\section{Conclusions}

The close agreement between observed and model-derived enhancements given in Table I points to the validity of the present linear model at the small octahedral stresses involved. The restriction of the present model to linear stress-strain-rate dependence suggests a further examination, theoretical and empirical, of non-linear effects. A preliminary model incorporating a power-law rheology predicts that an equivalent power exponent be applied to the linear enhancements. This result seems to be supported by additional uniaxial and simpleshear tests on isotropic and natural anisotropic aggregates now completed in the octahedral stress range between 0.05 and $1.6 \mathrm{MN} \mathrm{m}^{-2}$.

It may be concluded that the use of a flow law derived from laboratory studiec of isotropic ice to model flow in regions of natural ice masses exhibiting strong crystallographic anisotropy will lead to underestimates of actual strain-rates by a factor likely to be in excess of 10 . The 
enhancement factor described here offers an effective quantitative means of accounting for the major effects of crystallography. If, as field results suggest, the crystallographic fabric of natural ice masses is distributed in a systematic way throughout, then the enhancement factor, which depends on the local crystallographic fabric and stress situation, could be used in a flow law as a function of location.

\section{Acknowledgements}

The author is grateful to Dr William Budd of the Australian Antarctic Division for helpful comments regarding the model and to Neal Young, also of Antarctic Division, for his assistance with the laboratory work.

\section{REFERENCES}

Batchelor, G. K. 1967. An introduction to fluid dynamics. Cambridge, University Press.

Glen, J. W. 1958. The flow law of ice: a discussion of the assumptions made in glacier theory, their experimental foundations and consequences. Union Géodésique et Géophysique Internationale. Association Internationale d'Hydrologie Scientifique. Symposium de Chamonix, $16-24$ sept. 1958, p. 17 7 -83. (Publication No. 47 de l'Association Internationale d'Hydrologie Scientifique.)

Jaeger, J. C. [ [ ${ }^{\mathrm{r}}$ 969.] Elasticity, fracture and flow with engineering and geological applications. London, Methuen. (Methuen's Monographs on Physical Subjects.)

Kamb, W. B. I96r. The glide direction in ice. Journal of Glaciology, Vol. 3, No. 3o, p. 1097-1o6.

Langdon, T. G. I973. Creep mechanisms in ice. (In Whalley, E., and others, ed. Physics and chemistry of ice: papers presented at the Symposium on the Physics and Chemistry of Ice, held in Ottawa, Canada, 14-18 August 1972. Edited by E. Whalley, S. F. Jones, L. W. Gold. Ottawa, Royal Society of Canada, p. 356-6r.)

Nye, J. F. 1953. The flow law of ice from measurements in glacier tunnels, laboratory experiments and the Jungfraufirn borehole experiment. Proceedings of the Royal Society of London, Ser. A, Vol. 219 , No. I 139 , p. 477-89.

Taylor, G. I. 1956. Strains in crystalline aggregate. (In Grammel, R., ed. Internationale Union für Theoretische und Angewandte Mechanik. Verformung und Fliessen des Festkörpers. Kolloquium, Madrid, 26. bis 3o. September 1955. Berlin, etc., Springer-Verlag, p. 3-12.)

Weertman, J. I963. The Eshelby-Schoeck viscous dislocation damping mechanism applied to the steady-state creep of ice. (In Kingery, W. D., ed. Ice and snow; properties, processes, and applications: proceedings of a conference held at the Massachusetts Institute of Technology, February $12-16,1962$. Cambridge, Mass., M.I.T. Press, p. 28-33.)

Weertman, J. 1973. Creep of ice. (In Whalley, E., and others, ed. Physics and chemistry of ice: papers presented at the Symposium on the Physics and Chemistry of Ice, held in Ottawa, Canada, 14-18 August 1972. Edited by E. Whalley, S. F. Fones, L. W. Gold. Ottawa, Royal Society of Canada, p. 320-37.)

\section{DISGUSSION}

D. J. Goodman: Taylor's analysis suggests that five independent slip systems are required for plasticity. Your analysis discusses only the basal system which provides only three independent systems. Could you explain how you introduce the other two systems?

R. C. LILE: The degree to which basal glide alone is unable to account for accommodation in the aggregate is measured by the residual strain-rate, $\dot{a}_{i j}$. While additional systems are certainly required to supply the residual rate of strain, their effect on the aggregate fluidity can be determined in terms of the energy dissipated in association with the residual strain-rate. It may be that only the aggregate itself knows exactly what mechanisms are available and which are utilized. 